UDC 614.47:616.8

DOI: $10.21668 /$ health.risk/2020.3.22.eng

Read

online

Review

\title{
VACCINATION AGAINST SWINE FLU CAUSED NARCOLEPSY IN SEVERAL EUROPEAN COUNTRIES
}

\author{
I. Boström ${ }^{1}$, O. Lindberger ${ }^{2,3}$, M. Partinen ${ }^{4,5}$, A.M. Landtblom ${ }^{1,2}$ \\ ${ }^{1}$ Departments of Neurology and Clinical and Experimental Medicine, Linköping University, SE-581 83, \\ Linköping, Sweden \\ ${ }^{2}$ Department of Neurosciences, Uppsala University, 3 Husargatan Str., Uppsala, SE-752 36, Sweden \\ ${ }^{3}$ Uppsala Innovative Wellness Center Ekeby Hälsocenter, 21 Ekebi Bruk Str., Uppsala, SE-752 63, Sweden \\ ${ }^{4}$ Department of Neurological Sciences, University of Helsinki, 4 Haartmaninkatu Str., Helsinki, 00014, Finland \\ ${ }^{5}$ Helsinki Sleep Clinic, Vitalmed Research Centre, 3 Sitratori Str., Helsinki, 00420, Finland
}

\begin{abstract}
Narcolepsy is a rare sleeping disorder that gives sleep onset rapid eye movement periods and excessive daytime sleepiness. It is divided into two subgroups, narcolepsy type 1 where there also is orexin deficiency and cataplexy and narcolepsy type 2 that lack these features. Narcolepsy type 1 is assumed to be an autoimmune disease with destruction of orexin-producing cells. The pathology behind is unclear. There is a strong association to a class II HLA allele, HLADQB1*06:02 and the H1N1-virus and streptococcal infections has also been associated with narcolepsy. The severity of narcolepsy differs between patients from those who can manage their disease without medication to those who has a severe impact on their everyday life. There is a diagnostic delay between the onset of symptoms and time for diagnosis that in some cases can be more than a decade. The global mean prevalence is 30 per 100000 inhabitants. The incidence in children in northern Europe has risen since 2010. An early study of the 2009 H1N1 influenza A pandemic indicated a high mortality and prompted efforts to rapidly come up with a vaccine. One of these was Pandemrix that was the most widely used in Europe and $61 \%$ of the inhabitants in Sweden was vaccinated. Studies have shown an increased incidence of narcolepsy type 1 in European countries that had used Pandemrix, but no increased risk was seen in countries that had used other vaccines than Pandemrix.
\end{abstract}

Key words: narcolepsy, H1N1-virus, Pandemrix, incidence, prevalence, diagnostic delay.

Narcolepsy is a rare sleeping disorder giving excessive daytime sleepiness and falling asleep unwillingly during daytime, sleep onset rapid eye movement (REM) periods and might have automatic behaviour, hallucinations when waking up and falling asleep, sleep paralysis, periodic leg movements, psychiatric symptoms and increased weight [1-3]. In narcolepsy type 1 there is also cataplexy (emotions triggering loss of muscle tone) and orexin-deficiency, detectable in cerebrospinal fluid. Cataplexy and orexin-deficiency is not seen in narcolepsy type 2 [4]. In narcolepsy type 1 disrupted sleep with repeated awakenings during night is common [1].

Studies have shown that getting narcolepsy affects life in many domains; for children it affects their education, about half of the children get behavioural problems, the unemployment rates in adults are high and those who work have a lower income [1]. Many patients with narcolepsy complain about working memory problems, but studies have been contradictory and there is little objective evidence for a memory deficit. One study in adolescents found no memory deficits in patients compared

(C) Boström I., Lindberger O., Partinen M., Landtblom A.M., 2020

Inger Boström - PhD, Researcher, Division of Neurology, Department of Clinical and Experimental Medicine, Associate Professor (e-mail: inger.bostrom@liu.se; tel.: +461-328-10-00).

Oskar Lindberger - Professor at Department of Neurosciences (e-mail: sari.thunberg@neuro.uu.se; tel.: +461-86-11-50-34).

Markku Partinen - Professor, Director (e-mail: markpart@mac.com; tel.: +358-10-23-11-480; ORCID: https:// orcid.org/0000-0002-8182-9368).

Anne-Marie Landtblom - Professor at Department of Neuroscience (e-mail: anne-marie.landtblom@neuro.uu.se; tel.: +460-705-59-16-70; ORCID: https://orcid.org/0000-0001-9567-470X). 
to controls but suggested that the patients might have a dysregulation in sustained attention [5].

The incidence is 1 per 100.00 inhabitants per year but has risen in children in Northern Europe since 2010 [1, 4]. The global mean prevalence is 30 per 100.000 inhabitants, with the highest prevalence in Japan $\left(160 / 10^{5}\right)$ and the lowest in Israel $\left(0.23 / 10^{5}\right)$ which partly could be explained by genetics but also by the fact that the prevalence is calculated in different age span. Onset of narcolepsy is most common between 10 to 30 years, onset after 40 years of age is rare and before 2010 onset before the age of 10 was seldom reported [1].

There is a delay between onset of symptoms and diagnosis in narcolepsy that can be substantial, but there seems to be a trend towards a shorter delay [5-6]. Different studies report an average diagnostic delay between 8,4 to 16 years [7-13]. A literature review by Lindberger which included previous mentioned studies among others found that most studies show a diagnostic delay over one decade [14].

Diagnostic criteria according to ICSD-3 [1].

\section{Narcolepsy type 1.}

Criteria A and B must be fulfilled.

A. The patient has daily periods of irrepressible need to sleep or daytime lapses into sleep occurring for at least three months.

B. The presence of one or both of the following:

1. Cataplexy and a mean sleep latency of $\leq 8$ minutes and two or more sleep onset REM periods (SOREMPs) on a multiple sleep latency test (MSLT) performed according to standard techniques. A SOREMP within 15 minutes of sleep onset on the preceding nocturnal polysomnogram may replace one of the SOREMPs on the MSLT.

2. CSF hypocretin-1 concentration, measured by immunoreactivity, is either $\leq 110 \mathrm{pg} / \mathrm{mL}$ or $<1 / 3$ of mean values obtained in normal subjects with the same standardized assay.

\section{Narcolepsy type 2.}

Criteria A-E must be fulfilled.

A. Daily periods of irrepressible need to sleep or daytime lapses into sleep occurring for at least 3 months.
B. A mean sleep latency of $\leq 8$ minutes and two or more sleep onset REM periods (SOREMPs) are found on a MSLT performed according to standard techniques. A SOREMP within 15 minutes of sleep onset on the preceding nocturnal polysomnogram may replace one of the SOREMPs on the MSLT.

\section{No cataplexy.}

D. CSF hypocretin-1 concentration has not been measured or CSF hypocretin-1 concentration measured by immunoreactivity is either $>110 \mathrm{pg} / \mathrm{mL}$ or $>1 / 3$ of mean values obtained in normal subjects with the same standardized assay.

E. The hypersomnolence and/or MSLT findings are not better explained by other causes such as insufficient sleep, obstructive sleep apnea, delayed sleep phase disorder, or the effect of medication or substances or their withdrawal.

Treatment in Sweden.

In an expert meeting summoned by Swedish medical products agency in Sweden in February 2013 directions for the symptomatic treatment of narcolepsy was drawn. It is important that the patient has regular sleeping habits, avoid sleep deprivation, plans regular naps during the day and avoid meals rich in easily digestible carbohydrates. Support and advice from a treatment team with good knowledge of narcolepsy and treatment of comorbidity was also stressed as important [15].

Medical treatment of hypersomnia for adults consists of modafinil, methylphenidate or amphetamine. Methylphenidate can be combined with modafinil. Cataplexy in adults can be treated with natriumoxybate or antidepressants. Natriumoxybate can also reduce the frequency of nocturnal awakenings and reduce subjective daytime sleepiness. Antidepressants might have an effect on hallucinations and sleep paralysis associated to falling asleep and awakening [15]. Pitolisant belongs to a new class of drugs and has been showed to have an effect on cataplexy, daytime sleepiness, hallucinations and sleep paralysis in some patients $[16,17]$.

Hypersomnia in children and adolescents can be treated with modafinil or methylpheni- 
date. Antidepressants (mainly SSRI or SNRI) is used to treat cataplexy. Sleep disturbance is often treated with melatonin and sometimes with natriumoxybate [15].

It is assumed that narcolepsy type 1 is an autoimmune disease that results in orexindeficiency by destructions of neurons in the lateral hypothalamus that produce orexin but the pathology behind this is unknown. Cellmediated autoimmunity, autoantibodies or cytotoxicity has been proposed as possible mechanisms. Infection with the H1N1 virus and streptococcal infections has been associated with onset of narcolepsy [1, 4]. Another support for the autoimmune hypothesis is the presence of the class II HLA-allele HLADQB1 $06: 02$ in $98 \%$ of patients with narcolepsy type 1 . HLADQB1.06:02 is common in Western countries were $20-30 \%$ of the population has this allele, but still it has been estimated that it increases the risk of narcolepsy with about 250 times compared with non-carriers. Other genes have also been associated with narcolepsy and most of them are involved in the regulation of the immune system $[4,18]$.

Pandemrix and the risk of narcolepsy. An early observational study of the H1N1 influenza A pandemic in 2009 indicated that infection with the virus had a high mortality, especially in young people and pregnant women. This led to efforts to rapidly come up with an effective vaccine against the H1N1-type influenza A virus [4].

Pandemrix was the most widely used vaccine in Europe [4]. It was approved in line with European regulations for accelerated assessment. In Sweden about $61 \%$ of the inhabitants were vaccinated with Pandemrix between October 2009 and March 2010 but the vaccination coverage was higher in some groups, for instance in children, health workers and vulnerable patient groups [19]. In total there were eight different vaccines used in Europe [4]. Three of the them, including Pandemrix, had adjuvants which increase the effect of vaccines. Two vaccines had the adjuvant MF59 and Pandemrix had the adjuvant AS03 which was also used in Arepranrix, a vaccine used in Canada [20]. Two differences between Pandemrix and Arenpanrix was the amount of antigen that was higher in Pandemrix and differences in protein modifications and protein compositions between the two vaccines [4].

An increased incidence of narcolepsy type 1 was seen after Pandemrix-vaccination campaign in several European countries [1, 4]. In Sweden the first signals about an increased risk of narcolepsy in children vaccinated with Pandemrix came in June 2010 [19] and in Finland there was similar observations during the summer of 2010 [1]. An increased risk of narcolepsy after Pandemrix vaccination was seen in mainly children and young adults during a follow up period to 2011 with about a three to fourfold increased risk in people under 21 years of age at vaccination and an increased but lower risk for individuals of age 21-30 [19]. On the contrary no increased incidence of narcolepsy was seen in Saudi Arabia after vaccination with Pandemrix in November 2009, but the vaccination coverage is unknown [21].

In a cohort study Persson et al investigated if there were an increased risk of a number of autoimmune and neurologic diseases after vaccination with Pandemrix, for instance multiple sclerosis, polyneuropathy, epilepsy, rheumatoid arthritis, thyroid disease, myasthenia gravis and Addison's disease. The study showed an increased risk of narcolepsy after vaccination with Pandemrix but not for any other neurologic or autoimmune disease [22].

A meta-analysis and systematic review showed an increased incidence of narcolepsy in Finland, France, Ireland, Norway, the Netherlands, Norway, Sweden and United Kingdom where Pandemrix was used but no increased risk in countries that had used other vaccines including Arepanrix. For children and adolescents, the incidence was 5-14 times higher and for adults 3-7 times higher [20]. In China there was an increased incidence of narcolepsy after the 2009 H1N1-pandemic without vaccination $[1,4]$, but this has not been shown in other countries [4]. However, Trog- 
stad et al report a synergistic effect of infection with the H1N1-influenza virus and vaccination with Pandemrix on the risk of developing narcolepsy in Norwegians [23]. It is possible that a genetic susceptibility in combination with several environmental triggers, where Pandemrix acts as one of them, contributes to the onset of narcolepsy [1].

It has been suggested that individuals who has autoimmunity themselves or in their families might be at risk of getting auto-immune reactions after vaccination as well as people with genetic susceptibility and Sarkanen et al. suggest that, for instance, streptococcal infection could reduce self-tolerance temporarily in addition to vaccination [4].

The severity of post Pandemrix narcolepsy spans from individuals who don't need medication to manage their disease to very handicapped individuals and some people also get serious psychiatric symptoms [4]. Studies that has compared Pandemrix vaccinated and unvaccinated patients, mainly children, with narcolepsy type 1 has found a more rapid onset in vaccinated patients, that facial hypotonia and tongue protrusion was more common as a sign of cataplexy in vaccinated children [4] and that it was more common to have cataplexy as one of the initial symptoms in the vaccinated group as well as more than two initial symptoms [19]. A more disturbed nocturnal sleep was seen in Finnish children with post Pandemrix narcolepsy type 1 compared to unvaccinated Italian children with narcolepsy type 1 [3]. One study found that patients with post Pandemrix narcolepsy typ 1 had more frequent cataplexy and that $10 \%$ of patients with onset of narcolepsy before Pandemrix vaccination had worsening of cataplexy after vaccination with Pandemrix [3]. The clinical course of narcolepsy type 1 is wide and overall the clinical course seems to be similar between vaccinated and unvaccinated patients [3].

In countries where Pandemrix was used narcolepsy is considered an adverse event of the vaccination and patients who has developed narcolepsy after Pandemrix vaccination are compensated, but rules for compensation varies among the countries [3]. The time window for an increased risk of narcolepsy after Pandemrix vaccination has been estimated to two years after vaccination in studies in Sweden and Finland, but it is still unclear [4].

At our neurology clinic in Uppsala we frequently encountered narcolepsy patients who had diagnostic delays. For example, we found seven patients with Pandemrix related narcolepsy with diagnostic delays of nearly a decade. Previous misdiagnoses had been anaemia, asthma, psychosocial problems, depression and unspecified tiredness.

Conclusion. Pandemrix has been showed to increase the risk of narcolepsy in several studies with an estimated time window of two years. Narcolepsy can have a huge impact on everyday life and onset is primarily in young people. There is also a diagnostic delay which means that some individuals might be without necessary treatment for years before diagnosis. Since onset of narcolepsy can have a huge impact on a young individual's life and also give rise to comorbidity it is important to get a proper diagnosis as soon as possible. The notion that a vaccination might be a trigger for an autoimmune disease rises the importance of identifying possible risk factors in individuals to be considered in future vaccination campaigns.

Funding. The research was not granted any sponsor support.

Conflict of interests. The authors declare there is no any conflict of interests.

\section{References}

1. Partinen M., Kornum B.R., Plazzi G., Jennum P., Julkunen I., Vaarala O. Narcolepsy as an autoimmune disease: the role of H1N1 infection and vaccination. Current Neurology and Neuroscience reports, 2018, vol. 13, no. 6, pp. 600-613. DOI: 10.1016/S1474-4422(14)70075-4

2. Nordstrand S.E.H., Hansen B.H., Rootwelt T., Karlsen T.-I., Swanson D., Nilsen K.B., Knudsen S. Psychiatric symptoms in patients with post-H1N1 narcolepsy type 1 in Norway. SLEEPJ, 2019, vol. 42, no. 4, pp. 1-9. DOI: 10.1093/sleep/zsz008 
3. Sarkanen T., Alakuijala A., Partinen M. Clinical course of H1N1-vaccine-related narcolepsy. T. Sleep Medicine, 2016, vol. 19, pp. 17-22. DOI: 10.1016/j.sleep.2015.11.005

4. Sarkanen T., Alakuijala A., Julkunen I., Partinen M. Narcolepsy associated with Pandemrix Vaccine. Current Neurology and Neuroscience reports, 2018, vol. 18, pp. 43. DOI: 10.1007/s11910018-0851-5

5. Witt S.T., Drissi N.M., Tapper S., Wretman A., Szakács A., Hallböök T., Landtblom A.-M., Karlsson T. [et al.]. Evidence for cognitive resource imbalance in adolescents with narcolepsy. Brain Imaging and Behavior, 2018, vol. 12, no. 2, pp. 411-424. DOI: 10.1007/s11682-017-9706-y

6. Thorpy M.J., Krieger A.C. Delayed diagnosis of narcolepsy: characterization and impact. Sleep Med, 2014, vol. 15, no. 5, pp. 502-507. DOI: 10.1016/j.sleep.2014.01.015

7. Ingravallo F., Gnucci V., Pizza F., Vignatelli L., Govi A., Dormi A., Cicognani A., Dauvilliers Y., Plazzi G. The burden of narcolepsy with cataplexy: How disease history and clinical features influence socio-economic outcomes. Sleep. Med., 2012, vol. 13, no. 10, pp. 1293-1300. DOI: 10.1016/j.sleep.2012.08.002

8. BaHammam A.S., Alenezi A.M. Narcolepsy in Saudi Arabia. Demographic and clinical perspective of an under-recognized disorder. Saudi. Med. J., 2006, vol. 27, no. 9, pp. 1352-1357.

9. Morrish E., King M.A., Smith I.E., Shneerson J.M. Factors associated with a delay in the diagnosis of narcolepsy. Sleep. Med., 2004, vol. 5, no. 1, pp. 37-41. DOI: 10.1016/j.sleep.2003.06.002

10. Luca G., Haba-Rubio J., Dauvilliers Y., Lammers G.J., Overeem S., Donjacour C.E., Mayer G., Javidi S. [et al.]. Clinical, polysomnographic and genome-wide association analyses of narcolepsy with cataplexy: a European Narcolepsy Network study. J. Sleep. Res., 2013, vol. 22, no. 5, pp. 482-495. DOI: $10.1111 /$ jsr. 12044

11. Broughton R.J., Fleming J.A., George C.F., Hill J.D., Kryger M.H., Moldofsky H., Montplaisir J.Y., Morehouse R.L. [et al.]. Randomized, double-blind, placebo-controlled crossover trial of modafinil in the treatment of excessive daytime sleepiness in narcolepsy. Neurology, 1997, vol. 49, no. 2, pp. 444451. DOI: $10.1212 / \mathrm{wnl} .49 .2 .444$

12. Frauscher B., Ehrmann L., Mitterling T., Gabelia D., Gschliesser V., Brandauer E., Poewe W., Högl B. Delayed diagnosis, range of severity, and multiple sleep comorbidities: a clinical and polysomnographic analysis of 100 patients of the Innsbruck narcolepsy cohort. J. Clin. Sleep. Med., 2013, vol. 9, no. 8 , pp. $805-812$. DOI: $10.5664 /$ jcsm. 2926

13. Taddei R.N., Werth E., Poryazova R., Baumann C.R., Valko P.O. Diagnostic delay in narcolepsy type 1: combining the patients' and the doctors' perspectives. J. Sleep. Res., 2016, vol. 25, no. 6, pp. 709-715. DOI: $10.1111 /$ jsr.12420

14. Lindberger O. Characterizing the diagnostic delay in Narcolepsy: A literature review. Uppsala, Uppsala University Publ., 2019, 63 p.

15. Läkemedelsbehandling av narkolepsi - ett kunskapsdokument. Läkemedelsverket. Farmaceutical treatment of narcolepsy from Swedish medical products agency, 2013, vol. 24, no. 4, pp. 21-27.

16. Dauvilliers Y., Arnulf I., Szakacs Z., Leu-Semenescu S., Lecomte I., Scart-Gres C., Lecomte J.-M., Schwartz J.-Ch. [et al.]. Long-term use of pitolisant to treat patients with narcolepsy: Harmony III Study. SLEEPJ, 2019, vol. 42, no. 11, pp. 1-11. DOI: 10.1093/sleep/zsz174

17. Bolin K., Niska P.-Å., Pirhonen L., Wasling P., Landtblom A-M. The cost utility of pitolisant as narcolepsy treatment. Acta. Neurol. Scand., 2020, vol. 141, no. 4, pp. 301-310. DOI: 10.1111/ane.13202

18. Hallberg P., Smedje H., Eriksson N., H Kohnke., Daniilidou M., Öhman I., Yue Q.-Y., Cavalli M. [et al.]. Pandemrix-induced narcolepsy is associated with genes related to immunity and neuronal survival. EBioMedicine, 2019, vol. 40, pp. 595-604. DOI: 10.1016/j.ebiom.2019.01.041

19. Feltelius N., Persson I., Ahlqvist-Rastad J., Andersson M., Arnheim-Dahlström L., Berman P., Granath F., Adori C. [et al.]. A coordinated cross-disciplinary research initiative to address an increased incidence of narcolepsy following the 2009-2010 Pandemrix vaccination programme in Sweden. J. Intern. Med., 2015, vol. 278, pp. 335-353. DOI: 10.1111/joim.12391

20. Sarkanen T.O., Alakuijala A.P.E., Dauvilliers Y.A., Partinen M.M. Incidence of narcolepsy after H1N1 influenza and vaccinations: Systematic review and meta-analysis. Sleep Medicine Reviews, 2018, vol. 38, pp. 177-186. 
21. Qasrawi S.O., Albarrak A.M., Alharbi A.S., Nashwan S., Almeneessier A.S., Pandi-Perumal S.R., Alsaadi M.M., BaHammam A.S. Narcolepsy in Saudi patients before and after the 2009 H1N1 vaccination. The experience of 2 referral centers. Saudi. Med. J., 2017, vol. 38, no. 12, pp. 1196-1200. DOI: 10.15537/smj.2017.12.21046

22. Persson I., Granath F., Askling J., Ludvigsson J.F., Olsson T., Feltelius N. Risks of neurological and immune-related diseases, including narcolepsy, after vaccination with Pandemrix: a population- and registry-based cohort study with over 2 years of follow-up. J. Intern. Med., 2014, vol. 275, no. 2, pp. 172-190. DOI: 10.1111/joim.12150

23. Trogstad L., Bakken I.J., Gunnes N., Ghaderi S., Stoltenberg C., Magnus P., Håberg S.E. Narcolepsy and hypersomnia in Norwegian children and young adults following the influenza A(H1N1) 2009 pandemic. Vaccine, 2017, vol. 35, pp. 1879-1885. DOI: 10.1016/j.vaccine.2017.02.053

Boström I., Lindberger O., Partinen M., Landtblom A.M. Vaccination against swine flu caused narcolepsy in several european countries. Health Risk Analysis, 2020, no. 3, pp.180-185. DOI: 10.21668/health.risk/2020.3.22.eng

Received: 30.04 .2020

Accepted: 17.08 .2020

Published: 30.09 .2020 